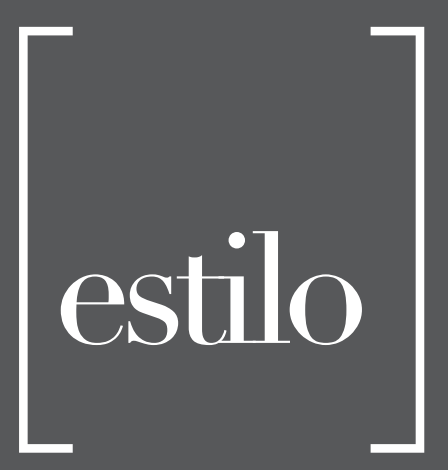

[ GILDA CHATAIGNIER ]

Graduada em Jornalismo pela UFRJ. Mestre em Artes e Design pela PUC-RJ. Professora e autora de vários livros, entre os quais se destacam Todos os caminhos da moda (Rio de Janeiro: Rocco, 1997) e Fio a Fio - tecidos, moda e linguagem (São Paulo: Editora Estação das Letras e Cores, 2007).

E-mail: gilda.chataignier@gmail.com

\title{
A moda na pós-modernidade
}

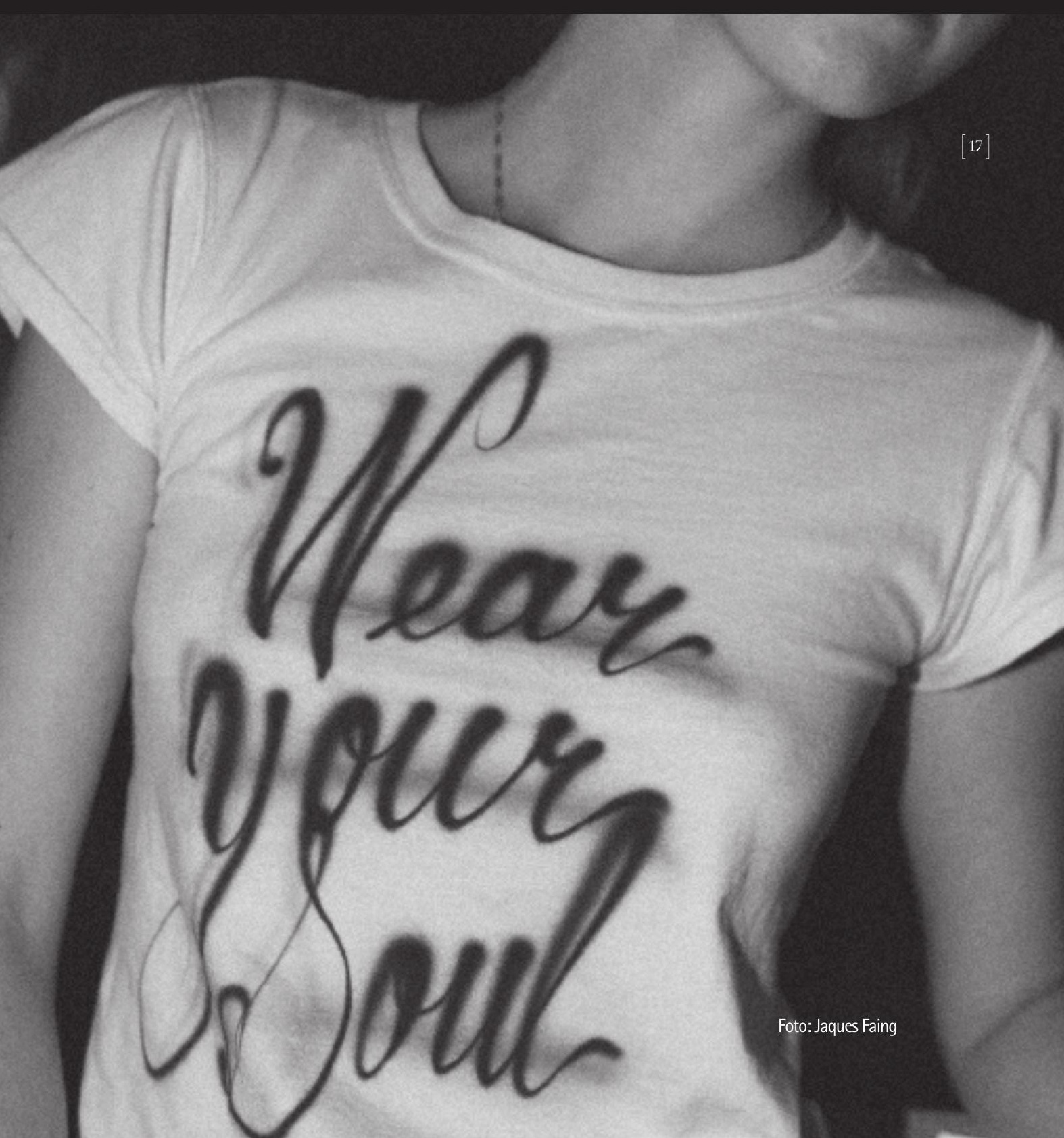


0 que mais se pode criar em matéria de moda, já que o ser humano continua bípede, mamífero, com uma só cabeça, com mais ou menos pêlos e cabelos e uma necessidade cada vez maior de cobrir-se, despir-se, enfeitar-se, aparecer, manter uma eterna juventude - seja por que meios for - e sair por aí com grifes coladas ao corpo? E falando de peças, não há mais o que se inventar. Mas a festa continua, a efemeridade e a rapidez com que se consome também aceleram o passo e a moda, todo-poderosa, quer mais, sempre. Estariamos vivendo nesse início do século XXI um processo de alienação, no qual a identidade de cada um estaria totalmente submissa e atrelada às roupas e à moda? Ou há um espaço em que se pode comemorar uma democracia feita com panos e estilos?

A complexidade da questão chega a ser perturbadora, uma vez que dentro desse quadro que vislumbramos com pinceladas caricaturais esconde-se uma perigosa encruzilhada no que diz respeito à moda. Seria assim mesmo a realidade da moda? Ou a moda acabou, sufocada por tantas demandas e incapaz de atender aos seus súditos, elas e eles também? 0 que queremos falar, quem sabe tentar discutir, é que essa imagem que ilustra e distorce o mundinho fashion, com seus típicos exageros, insuflação de egos e uma permanente competição, altera os códigos que poderiam, quem sabe, ser seguidos tendo como bases a construção de um segmento maior, mais acessível, mais criativo e mais harmonioso.

Para sermos bem críticos, devemos procurar entender melhor o estágio em que se encontra a moda, tendo como ponto de partida a chamada pós-modernidade e sua estrada que permeia o século XXI.

Segundo Steven Connor, um dos mais afamados teóricos da comunicação e da pós-modernidade, "uma das mais notáveis e representativas áreas da teoria pós-moderna da cultura popular é a moda". Vale observar que a moda é vista como cultura popular, não mais como uma atividade elitista e fechada em torno de cadeirinhas douradas e passarelas vermelhas (como nas maisons de alta-costura em Paris) ou nos megadesfiles nos quais só entra quem tem a senha de um poder discutível, aqui, na Europa ou na Terra do Nunca.

Roland Barthes, de acordo com Connor, foi o primeiro a compreender o funcionamento da moda como linguagem, com suas próprias regras e estruturas. Alguma coisa muito além de lacinhos, repuxados, decotes e atitudes.

A história recente da moda - entendendo como tal as expressões difundidas e pensadas ao longo do século XX - ganhou espaço através dos olhares representativos de diversos profissionais de áreas ligadas à estética, tais como Mies van der Rohe (1886-1969): arquiteto alemão chamado de "o encantador de Berlim", por causa de suas construções que pareciam baladas ao vento, responsável também por incriveis cúpulas de cristal de alguns arranha-céus em Nova York e Chicago; Piet Mondrian (1872-1944): pintor holandês que flertou com o impressionismo, simbolismo, pontiIhismo e cubismo e acabou desenvolvendo seu forte, independente e abstrato estilo, no qual Saint Laurent se inspirou para criar o famoso vestido Mondrian, em 1965; Walter Gropius (1883-1969): arquiteto americano de origem alemã, designer - um dos fundadores da famosa escola de Bauhaus - urbanista e professor, cuja obra se inscrevia na racionalização, novas tecnologias e materiais) e outros, como Victor Tatlin (1843-1919): francês, o primeiro a perceber o aparato do corpo em relação à moda; o teórico Alfred Loos, Jacobus Oud e até mesmo uma mulher diretamente ligada à moda, Sonia Delaunay. Essa artista plástica, francesa de origem russa, instalou-se em Paris em 1905 e seus interesses e criações voltavam-se para áreas afins com a moda, tais como decoração de interiores, teatro e figurino, estamparia têxtil e colorismo. Considerada uma visionária, Delaunay achava que a moda devia evoluir no sentido da democracia e criou um desenvolvimento de peças que tinha como base a criação simultânea: misturava tecidos com tramas e texturas diferentes, como também diferentes eram os materiais, as cores e os usos. Uma espécie de improviso que remetia a um maestro diante de sua orquestra ou ao pincel de um pintor defronte a sua tela. Mais atual, impossivel!

Outra mulher que sinaliza muito a moda contemporânea é a inglesa Elizabeth Wilson, historiadora especializada em moda. Ela vê a pós-modernidade como uma coerência entre sensibilidade fragmentada e obsessão pelo superficial e pela novidade. 
Para ela, a estética pós-moderna é feita de fragmentos que se unem, muitas vezes com origens diversas. Outros autores, como Peter Wollen, argumentam que existe toda uma história alternativa no modernismo, cujas primeiras experiências vieram impregnadas com o balé russo. Wollen admite que todas as manifestações de moda pós-modernistas encontram vínculos com "antigas novidades", como a ligação entre o balé russo e o punk, a cultura de rua com as excentricidades finais do ancien regime y compris, as loucuras adolescentes da rainha Maria Antonieta.

A fragmentação que aparece em diversos segmentos, não sendo privilégio da moda, fica muito associada à bricolagem, à justaposição improvável de fragmentos "cacos de uma civilização", como diria Chico Buarque - que formam, em seu conjunto, um caleidoscópio fascinante: o que se viu bastante na SP Fashion Week e no Fashion Rio e, antes, nas capitais da moda, como Paris, Milão e Roma, Londres e Nova York, que captam esse universo de bricoleurs.

0 papel da moda que não pode inventar sutiãs de biquínis para quatro seios, calças com múltiplas pernas ou vestidinhos transparentes para homens que empunham espada, reside no fato de mudar os caminhos tradicionais: confundir categorias, romper com antigos preconceitos, colocar borderlines no foco de espetáculos, provocar a moral e outras atitudes antes impensadas.

Dentro desse contexto, o feio não existe, o bonito é o que vende e se ele vende é porque agrada. E se agrada não importa a sua dimensão do belo. Nessa mudança de caminho, valores diferentes se inscrevem no campo da moda. Não necessariamente novíssimos, mas vistos com óticas pós-contemporâneas: como se o porvir se antecipasse no tempo e invadisse a saga eterna de dias e noites.

Alguns exemplos desse panorama instigante que mobiliza novos criadores, jovens estudantes de moda e pessoas com criatividade à flor da pele:

- uso indiscriminado de peças provenientes dos gêneros opostos (masculino e feminino): cueca, gravata, maquilagem, adereços como grandes bijuterias ou bolsas.

- pirâmide social invertida: a moda segue as influências do morro, do asfalto, das ruas e das tribos urbanas, projetando-as para as elites.

- a intensa participação popular nos sofisticados redutos de moda.

- o glamoursuburbano traduzido nos tecidos populares, mas enfeitados com efeitos cinematográficos: chitão, liganete, renda, tule de náilon, rayon, cetim de carnaval, pelúcia.

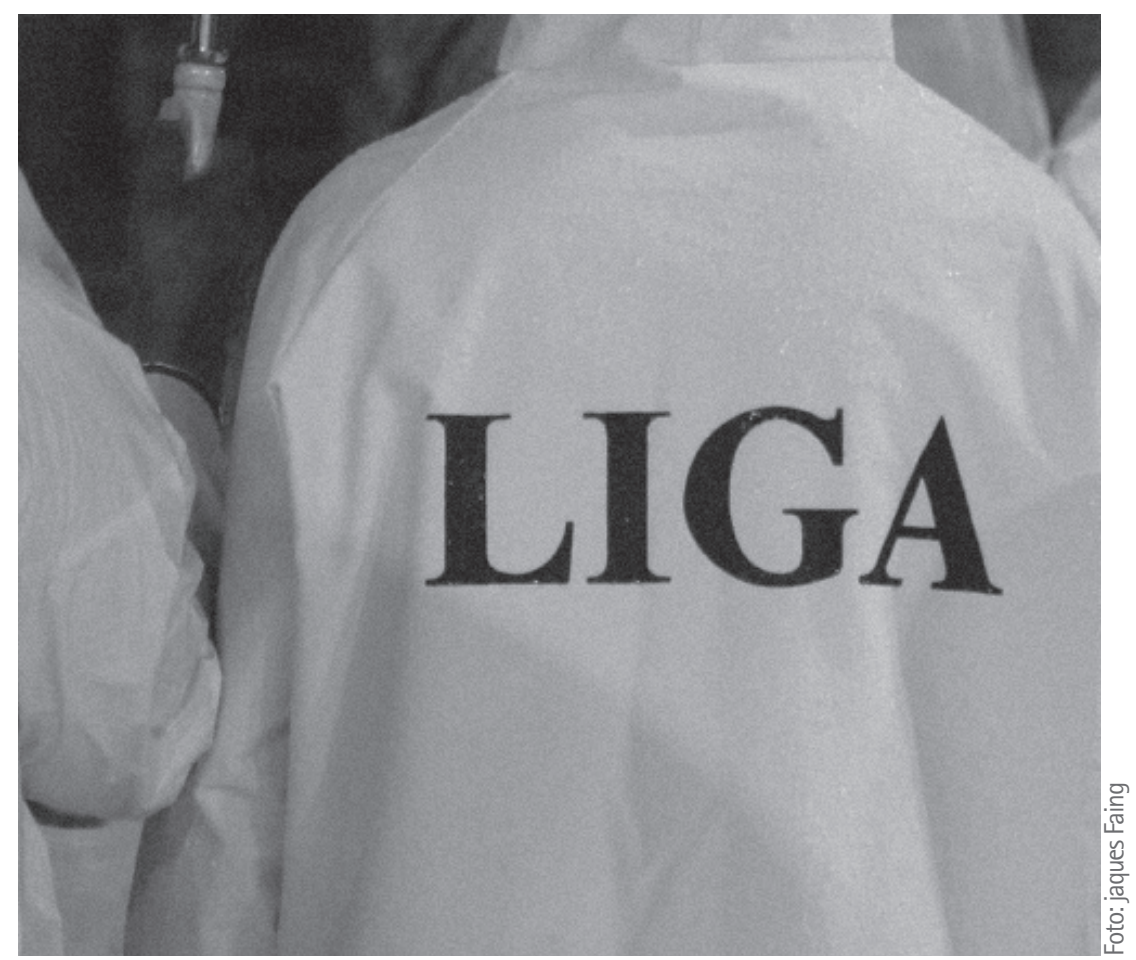


- acessórios de boneca ou de cigana, nos quais brilham o plástico, o vinil, o falso brilhante, as pedras de vidro, o colorido descartável.

- o exagero nos múltiplos adereços e inversões de usos (flor no calcanhar, peças pelo avesso, etc.).

- infantilização em modelos, acessórios, calçados e atitudes. Uma espécie de fonte da juventude traduzida em ícones de quadrinhos, como mangás, do cinema e da televisão.

- a celebração de peças consideradas deselegantes, como vestidos caseiros que inspiraram no pós-guerra a aparição do prêt-à-porter.

- a escolha consciente do homem comum como modelo (ainda há exceções) para fotos ou passarela; a mulher não entra nessa visão, pois precisa ser belíssima e macérrima.

- a sofisticação blasée negligente do estilo que ilustra corpos, vitrinas e passarelas. Trapinho? Nem pensar! É fashion mesmo.

- a obsolescência planejada a curto prazo e sem garantia de sobrevida: o descartável. No futuro próximo não haverá mais espaço para brechós, salvo as peças de alta qualidade, o que provavelmente não acontecerá, pois passarão de mães para filhas, como nos séculos XVII e XVIII: roupas eram bens colocados em testamentos ao lado de terras, casas, móveis e jóias.

As contradições entram também nas questões ligadas à tecnologia de ponta que qualificam peças do vestuário, máquinas e outros itens responsáveis pelo desenvolvimento de tudo aquilo que se relacione com a moda. Ainda que a indústria têxtil desenvolva tecidos de altíssima tecnologia, não existe disponibilidade de acesso para o consumidor. Essas pequenas maravilhas são apenas possiveis nas aquisições das grandes empresas que fabricam moda com grife. É inviável comprar um corte de tecido que controle os batimentos cardíacos ou que nos faça dormir e sonhar. As lojas de tecidos estão fechando as portas ou mudando de ramo. 0 negócio é esperar o futuro nas grandes lojas.

0 novo também enaltece calçados que transformam o couro em plástico e as peles de animais selvagens limitam-se a jacarés e peixes que morrem sem dor. Mas a qualidade é uma condição sine qua non, ainda que a grande maioria dos produtos seja feita para durar pouco; o que vale mesmo é a aparência, a cópia de peças autênticas, a pirataria sem vergonha, aqui e ali.

Em todo esse quadro plural e às vezes contraditório, o vencedor é ainda o homem, que assume um duplo papel de criador e de consumidor, procurando através do trabaIho, da inteligência, da experiência e da originalidade, inovar os caminhos da moda no portal recém-aberto do século XXI. E se aproxima de gestores, desde o que abastece o almoxarifado ao que controla duplicatas ou prevê falências. Torcendo para aparecer na mídia, nem que seja em um classificado.

Quem viver verá!

\section{REFERÊNCIAS}

BARTHES, Roland. 0 óbvio e o obtuso. Lisboa: Edições 70, 1982

O'CONNOR, Steven. Cultura pós-moderna - introdução às teorias. São Paulo: Editora Loyola, 1993. 